\title{
ROOT CARIES IN AREAS WITH AND WITHOUT FLUORIDATED WATER AT THE SOUTHEAST REGION OF SÃO PAULO STATE, BRAZIL
}

\author{
Lilian Berta RIHS ${ }^{1}$, Maria da Luz Rosário de SOUSA², Ronaldo Seichi WADA ${ }^{2}$
}

1- DDS, MSc, Graduate student, Department of Community Dentistry, Dental School of Piracicaba, State University of Campinas, SP, Brazil.

2- DDS, MS, PhD, Chair Professor, Department of Community Dentistry, Dental School of Piracicaba, State University of Campinas, SP, Brazil.

Corresponding address: Dra. Maria da Luz Rosário de Sousa - Departamento de Odontologia Social, Faculdade de Odontologia de Piracicaba, Universidade Estadual de Campinas. Avenida Limeira 901 - Bairro Areião - 13414-018 - Piracicaba, SP, Brasil - Phone 55-19-3421-5364

e-mail: luzsousa@fop.unicamp.br

Received: February 9, 2007 - Modification: May 8, 2007 - Accepted: November 19, 2007

\begin{abstract}
7

his study aimed to investigate root caries prevalence in areas with and without water fluoridation at the Southeast region of São Paulo State, in the adult population, employees of public and private schools, and elderly population. Epidemiological surveys were conducted according to the World Health Organization guidelines (1997), including 1,475 dentate individuals aged 35 to 44 years and 65 to 74 years, living in cities representing the southeast of São Paulo State, with (n=872) or without $(n=603)$ fluoridated water supply. Statistical analysis was performed by Mann-Whitney and Chi-square tests at a significance level of 5\%. The prevalence of root caries was $15.6 \%$ for the 35-44-year-old age group and 31.8\% for the 65-74-year-old age group . There were no statistically significant differences $(p>0.05)$ in the occurrence of root caries according to water fluoridation, although individuals living at non-fluoridated areas presented higher percentage of missing teeth; also, there was higher mean number of intact roots at fluoridated areas $(\mathrm{p}<0.05)$. Most individuals with gingival recession, both adults and elderly, did not have root caries experience. In this study, root caries prevalence was lower in areas with fluoridated water. Due to the reduced prevalence of edentulism and increased number of people keeping their natural teeth for a longer period, a future increase in root caries is expected, highlighting the importance of studies related to water fluoridation and its relationship with the oral health of adults and elderly, especially referring to tooth root.
\end{abstract}

Uniterms: Oral health. Root caries. Fluoridation.

\section{INTRODUCTION}

Much emphasis has been given to the reduction in coronal caries experience in children. However, the international literature is controversial as to caries rates in adult and elderly populations. Some studies demonstrate improved oral health conditions with reduced occurrence of caries and edentulism ${ }^{4,10,15}$, while others report that geriatric populations have poor oral health status and high caries prevalence, including root caries ${ }^{6,12,18}$.

The occurrence of root caries has been increasingly reported in the last decades, and it has been shown to increase proportionally with age $6,12,14,15,17$. It should be highlighted that, in some areas, the occurrence of root caries has been considered a public health problem ${ }^{13}$, and some authors mention root caries as a risk factor for tooth loss in the age group above 60 years ${ }^{5,19}$.

Studies have reported the importance of water fluoridation on root caries prevalence ${ }^{8,14,22}$, yet such studies are scarce in Brazil. Thus, it is important to investigate the beneficial effect of water fluoridation not only for children, but also for adults and elderly in the Brazilian context. Therefore, this study investigated the prevalence of root caries in areas with and without water fluoridation at the Southeast region of São Paulo State, in adult individuals, employees of public and private schools, and elderly population.

\section{MATERIALAND METHODS}

The research protocol was first reviewed and approved by the Institutional Review Board of São Paulo Public Health School (COEP 62/98).

This cross-sectional study was conducted at the State of São Paulo, Southeast region of Brazil, in 1998. The study was performed on 29 randomly selected cities, including 16 with fluoridation of public water supply and 13 non- 
fluoridated cities. These 29 cities corresponded to 4 areas of the Regional Health Directions (DIRs) at the regions of Campinas (DIR XII), Piracicaba (DIR XV), São João da Boa Vista (DIR XX) and Sorocaba (DIR XXIII).

Random selection of cities according to the presence of water fluoridation was performed according to official records available at the time ${ }^{16}$. The onset of water fluoridation in the cities ranged from 1972 to 1991 ; most cities initiated water fluoridation in the $1980 \mathrm{~s}$.

The codes employed for investigation of root caries followed the guidelines of the World Health Organization ${ }^{22}$. Root caries prevalence was considered as the percentage of people presenting this type of lesion. This condition was also evaluated by mean number of decayed and/or filled roots (DF-R), in addition to the mean of each of these components individually, namely mean number of decayed roots (D-R), mean number of filled roots (F-R) and mean number of intact roots despite the presence of gingival recession (S-R). These variables were assessed according to age group (35-44 years old and 65-74 years old) and gender (male and female).

Examinations were performed by 33 dental professionals submitted to a 40-hour calibration, including theoretical discussions and practical activities, which simulated the situations experienced during practical work. The consensus technique was adopted, as recommended by the general coordination of the study. Inter-examiner agreement for dental caries was evaluated in the Southeast region, divided into four areas, revealing the following values: $84 \%, 96.5 \%$, $96.7 \%$ and $99.2 \%$. Values above $90 \%$ are considered good agreement, thus validating the outcomes; values of $80 \%$ to $89 \%$ indicate moderate agreement.

The percentage of intra-examiner agreement was calculated during data collection, by reexamination of $10 \%$ of the sample. The values obtained were $95.0 \%, 99.8 \%$ and 99.9\%; the results were not obtained for one area.

The subjects included elementary school teachers and employees of public and private schools, aged 35 to 44 years old, who were examined at work; and elderly aged 65 to 74 years old, attending health services or associations, who were examined at these places. The sample comprised only dentate individuals.

For the group of adults, individuals were selected by systematic probability sampling (all schools were included in cities with less than 20 schools) and a signed informed consent form was obtained form each participant. Elderly were selected among all individuals attending associations or municipal health services from October to December 1998.

Edentulous individuals and incomplete epidemiological survey forms were excluded from the study. This led to a final sample of 1,475 valid examinations.

Statistical analysis was performed by Mann-Whitney test for comparisons among means of DF-R and its components (D-R and F-R), S-R and mean number of present teeth according to presence or not of fluoridated water. Chisquare test was used to evaluate the mean number of present teeth according to the presence/absence of water fluoridation. Significance level was set at $5 \%$.

\section{RESULTS}

Table 1 presents the number of dentate individuals examined at the Southeast region of São Paulo State who were effectively included in the study, according to water fluoridation and gender.

Variables, such as mean number of present teeth and percentage of missing teeth in the DMFT index, were also investigated according to fluoridation of public water supply, as presented in Table 2. In the adult group, areas with fluoridated water showed a higher mean number of present teeth and lower mean number of missing teeth. In areas without fluoridated water, the elderly showed higher percentage of missing teeth. Regardless of water fluoridation, both adults and elderly presented more missing teeth than women $(\mathrm{p}<0.05)$. Among the elderly, in areas with fluoridated water, men showed more missing teeth $(\mathrm{p}<0.001)$. In the elderly group, only in fluoridated areas, women presented less missing teeth $(\mathrm{p}<0.001)$.

The prevalence of root caries for the 35-44-year-old age group was $17.3 \%(n=111)$ and $13.0 \%(n=53)(p=0.578)$, respectively, for populations living in cities at the Southeast region with or without water fluoridation. For the 65-74year-old age group, the prevalence was $33.8 \%(n=78)$ and $29.4 \%(n=57)(p=0.333)$, respectively, for fluoridated and nonfluoridated areas.

Results on the occurrence of root caries relative to water fluoridation and gender are presented in Table 3, according

TABLE 1- Dentate individuals according to fluoridated $(\mathrm{Fl})$ and non-fluoridated (Non-FL) water, age group and gender. Southeast Region of São Paulo State, 1998

\begin{tabular}{lllll}
\hline Age group & & FIn (\%) & Non-FIn (\%) & Total n (\%) \\
\hline \multirow{2}{*}{ 35 -44 years old } & & $641(61.0)$ & $409(39.0)$ & $1,050(100)$ \\
& Male & $135(55.8)$ & $107(44.2)$ & $242(100)$ \\
& Female & $506(63.0)$ & $302(37.0)$ & $808(100)$ \\
$\mathbf{6 5 - 7 4}$ years old & & $231(54.4)$ & $194(45.6)$ & $425(100)$ \\
& Male & $97(52.2)$ & $89(47.8)$ & $186(100)$ \\
& Female & $134(56.1)$ & $105(43.9)$ & $239(100)$ \\
\hline
\end{tabular}


TABLE 2- Number of present teeth and percentage of tooth loss (M-T component of DMF-T) according to age group and fluoridated (FI) and Non-fluoridated (Non-FI) water. Southeast Region of São Paulo State, 1998

Mean Number of present teeth

\begin{tabular}{|c|c|c|c|c|c|c|c|}
\hline & & $\mathrm{FI}$ & Non-FI & $p^{*}$ & $\mathrm{FI}(\%)$ & Non-FI (\%) & $p^{*}$ \\
\hline \multirow[t]{3}{*}{$35-44$ years old } & & $22.1^{\mathrm{a}}$ & $19.9^{b}$ & $<0.001$ & $36.5^{a}$ & $45.4^{b}$ & $<0.001$ \\
\hline & Male & $22.0^{\mathrm{a}}$ & $20.5^{b}$ & $<0.001$ & $45.1^{a}$ & $47.6^{a}$ & 0.08 \\
\hline & Female & $22.2^{\mathrm{a}}$ & $19.7^{b}$ & $<0.001$ & $34.4^{a}$ & $44.6^{\mathrm{b}}$ & $<0.001$ \\
\hline \multirow[t]{3}{*}{$65-74$ years old } & & $9.4^{\mathrm{a}}$ & $9.8^{a}$ & 0.23 & $78.6^{a}$ & $82.5^{b}$ & $<0.001$ \\
\hline & Male & $8.7^{a}$ & $12.7^{b}$ & $<0.001$ & $81.7^{a}$ & $78.0^{\mathrm{b}}$ & 0.003 \\
\hline & Female & $9.9^{a}$ & $7.4^{\mathrm{b}}$ & $<0.001$ & $76.4^{a}$ & $85.9^{b}$ & $<0.001$ \\
\hline
\end{tabular}

Means followed by different letters in the same line differ in relation to fluoridated water $(p<0.05$; Chi-square test).

TABLE 3- Root condition according to age group, gender and fluoridated (FI) and non-fluoridated (Non-FI) water. Southeast Region of São Paulo State. 1998

\begin{tabular}{|c|c|c|c|c|c|c|c|c|c|c|c|c|}
\hline \multirow{2}{*}{$\begin{array}{l}\text { Variables } \\
\text { Age group }\end{array}$} & \multicolumn{3}{|c|}{ DF-R } & \multicolumn{3}{|c|}{ D-R } & \multicolumn{3}{|c|}{ F-R } & \multicolumn{3}{|c|}{ S-R } \\
\hline & $\begin{array}{l}\text { FI } \\
(s d)\end{array}$ & $\begin{array}{l}\text { Non-FI } \\
\text { (sd) }\end{array}$ & $\mathbf{p}^{*}$ & $\begin{array}{l}\text { FI } \\
(s d)\end{array}$ & $\begin{array}{l}\text { Non-FI } \\
\text { (sd) }\end{array}$ & $\mathbf{p}^{*}$ & $\begin{array}{l}\text { FI } \\
(s d)\end{array}$ & $\begin{array}{l}\text { Non-FI } \\
\text { (sd) }\end{array}$ & $\mathbf{p}^{*}$ & $\begin{array}{l}\mathrm{Fl} \\
(\mathrm{sd})\end{array}$ & $\begin{array}{l}\text { Non-FI } \\
\text { (sd) }\end{array}$ & $\mathbf{p}^{*}$ \\
\hline $\begin{array}{r}35-44 \\
\text { years old }\end{array}$ & $\begin{array}{l}0.39^{\mathrm{a}} \\
(1.32)\end{array}$ & $\begin{array}{l}0.30^{\mathrm{a}} \\
(1.04)\end{array}$ & 0.059 & $\begin{array}{l}0.22^{a} \\
(1.13)\end{array}$ & $\begin{array}{l}0.12^{\mathrm{a}} \\
(0.48)\end{array}$ & 0.169 & $\begin{array}{l}0.18^{a} \\
(0.68)\end{array}$ & $\begin{array}{l}0.18^{a} \\
(0.87)\end{array}$ & 0.296 & $\begin{array}{l}4.10^{\mathrm{a}} \\
(5.88)\end{array}$ & $\begin{array}{l}2.95^{\mathrm{b}} \\
(4.70)\end{array}$ & 0.004 \\
\hline male & $\begin{array}{l}0.56^{a} \\
(1.20)\end{array}$ & $\begin{array}{l}0.39^{a} \\
(1.18)\end{array}$ & 0.135 & $\begin{array}{l}0.36^{a} \\
(0.89)\end{array}$ & $\begin{array}{l}0.21^{a} \\
(0.64)\end{array}$ & 0.132 & $\begin{array}{l}0.21^{\mathrm{a}} \\
(0.82)\end{array}$ & $\begin{array}{l}0.19^{a} \\
(1.03)\end{array}$ & 0.401 & $\begin{array}{l}6.33^{a} \\
(7.01)\end{array}$ & $\begin{array}{l}4.50^{\mathrm{a}} \\
(5.43)\end{array}$ & 0.093 \\
\hline female & $\begin{array}{l}0.35^{a} \\
(1.35)\end{array}$ & $\begin{array}{l}0.27^{a} \\
(0.99)\end{array}$ & 0.138 & $\begin{array}{l}0.18^{a} \\
(1.19)\end{array}$ & $\begin{array}{l}0.9^{\mathrm{a}} \\
(0.41)\end{array}$ & 0.381 & $\begin{array}{l}0.17^{a} \\
(0.64)\end{array}$ & $\begin{array}{l}0.18^{a} \\
(0.82)\end{array}$ & 0.499 & $\begin{array}{l}3.51^{a} \\
(5.40)\end{array}$ & $\begin{array}{l}2.40^{\mathrm{b}} \\
(4.29)\end{array}$ & 0.003 \\
\hline $\begin{array}{r}65-74 \\
\text { Years old }\end{array}$ & $\begin{array}{l}1.05^{\mathrm{a}} \\
(2.23)\end{array}$ & $\begin{array}{l}0.54^{a} \\
(1.15)\end{array}$ & 0.096 & $\begin{array}{l}0.69^{a} \\
(2.0)\end{array}$ & $\begin{array}{l}0.34^{a} \\
(0.9)\end{array}$ & 0.411 & $\begin{array}{l}0.36^{\mathrm{a}} \\
(1.11)\end{array}$ & $\begin{array}{l}0.21^{a} \\
(0.68)\end{array}$ & 0.319 & $\begin{array}{l}4.69^{a} \\
(5.97)\end{array}$ & $\begin{array}{l}4.27^{\mathrm{a}} \\
(5.80)\end{array}$ & 0.434 \\
\hline male & $\begin{array}{l}1.38^{\mathrm{a}} \\
(2.80)\end{array}$ & $\begin{array}{l}0.61^{\mathrm{a}} \\
(1.29)\end{array}$ & 0.077 & $\begin{array}{l}1.20^{\mathrm{a}} \\
(2.68)\end{array}$ & $\begin{array}{l}0.44^{\mathrm{b}} \\
(1.17)\end{array}$ & 0.036 & $\begin{array}{l}0.19^{a} \\
(0.74)\end{array}$ & $\begin{array}{l}0.17^{a} \\
(0.61)\end{array}$ & 0.700 & $\begin{array}{l}4.76^{a} \\
(6.53)\end{array}$ & $\begin{array}{l}5.76^{a} \\
(6.64)\end{array}$ & 0.208 \\
\hline female & $\begin{array}{l}0.81^{a} \\
(1.68)\end{array}$ & $\begin{array}{l}0.49^{a} \\
(1.02)\end{array}$ & 0.469 & $\begin{array}{l}0.32^{\mathrm{a}} \\
(1.17)\end{array}$ & $\begin{array}{l}0.25^{a} \\
(0.59)\end{array}$ & 0.383 & $\begin{array}{l}0.49^{a} \\
(1.30)\end{array}$ & $\begin{array}{l}0.24^{a} \\
(0.74)\end{array}$ & 0.169 & $\begin{array}{l}4.63^{a} \\
(5.56)\end{array}$ & $\begin{array}{l}3.01^{\mathrm{b}} \\
(4.59)\end{array}$ & 0.012 \\
\hline
\end{tabular}

Means followed by different letters in the same line differ in relation to fluoridated water $(p<0.05$; Mann-Whitney test).sd= standard deviation.

$\mathrm{DF}-\mathrm{R}=$ mean number of decayed and filled roots; $\mathrm{D}-\mathrm{R}=$ mean number of decayed roots; $\mathrm{F}-\mathrm{R}=$ mean number of filled roots; $\mathrm{S}-\mathrm{R}=$ mean number of exposed yet sound roots.

to the mean number of decayed and filled roots (DF-R), in addition to stratification of DF-R components, namely mean number of decayed roots (D-R) and mean number of filled roots (F-R), as well as mean number of exposed yet intact roots $(\mathrm{S}-\mathrm{R})$.

\section{DISCUSSION}

In Brazil, dental treatment in public health centers prioritizes school age children and the improvement of oral health in this age range, in a general way. On the other hand, adult and elderly patients have a great demand for treatment and often look for tooth extraction, which has a relatively low cost, fast resolution and can be performed in public health centers. This lack of access to preventive care is one of the several factors that can lead to tooth loss in the adult and elderly populations. These two groups can benefit from fluoridated water for control of dental caries, more specifically root caries. However, this benefit may be partial, since many teeth were missing in these individuals.

The present cross-sectional study employed secondary data from the Oral Health Epidemiological Survey of the State of São Paulo - 1998, which planned the sample size according to the prevalence of coronal caries; however, this study investigated root caries. The adult population comprised a specific category of employees and thus the results cannot be extrapolated for the Southeast region as a whole. Since elderly populations usually present relatively low number of remaining teeth, the results of this group 
should be carefully interpreted because the reduced number of present teeth can underestimate root caries prevalence, considering that more severe cases of root caries might demand tooth extraction.

However, in this study, water fluoridation was not a differential factor for edentulism in any age group, unlike the findings of O'Mullane, et al. ${ }^{15}$ (1996), who reported that both adult and elderly individuals living in fluoridated areas presented lower percentage of edentulism. Notwithstanding, the M-T component of the DMFT index was higher for individuals living in non-fluoridated areas (Table 2), as demonstrated in other studies ${ }^{7,18}$. This result may imply that, in the Southeast region, elderly males (Table 3 ) presented lower root caries prevalence because these individuals had a smaller number of teeth, possibly due to early loss, which may be related to dental caries, especially coronal caries, even though this was not addressed in the present study. It may be assumed that coronal caries led to tooth loss before root caries occurred.

In addition to dental caries, tooth loss in these two groups of individuals can be related to several other factors, e.g. periodontal disease, which causes loss of bone support; dental trauma; fractures; and lack of access to oral health services. In this study, it is difficult to clearly present the real causes of tooth loss. This point was confirmed by Imazato, et al. ${ }^{9}$ (2006), who observed that the number of decayed or filled lesions increased as the number of remaining teeth increased. Furthermore, the same authors reported that the presence of carious lesions may be related to dry mouth and brushing frequency, as risk factors associated with the presence of root caries.

Several international studies have reported that the proportion of adults keeping their natural teeth was higher in fluoridated communities compared to non-fluoridated areas $^{3,13,15,18,19}$, as observed in the present study. Marthalerm, et al. ${ }^{11}$ (1996) reported a dramatic reduction in the amount of prosthetic services delivered to elderly in fluoridated regions of Switzerland, which indirectly represents maintenance of natural teeth by this population.

Due to the unreliable establishment of the cause of tooth loss in adults, especially elderly, the DMFT index is not a safe measurement for caries evaluation as it is for children. Consequently, the interpretation of DMFT data for adults is difficult, highlighting the need to develop other indices to verify the oral health status in adult patients, especially addressing the root surface.

In the present study, the prevalence of root caries was not statistically dependent on the presence of water fluoridation for either of the age groups. Conversely, previous studies have reported an inversely proportional relationship between the prevalence of root caries and exposure to fluoridated water ${ }^{1,8,15,19}$, as also observed for the mean number of filled roots (F-R). Additionally, adults living in fluoridated areas had higher mean number of sound roots, i.e. maintenance of intact roots even in the presence of root exposure, which may represent a possible beneficial effect of this method for this age group (Table 3 ). In the same table, among the elderly, it can be observed that the mean of roots caries (D-R) was smaller in areas without fluoridated water, which can be apparently controversial. However, the standard deviation was high for several components of the DF-R, and these results can interfere with evaluation of these data. Thus, caution is recommended in the analysis of these conditions.

When the variables DF-R, D-R, F-R and S-R were stratified according to gender, for both adults and elderly, women living in fluoridated areas presented higher mean number of exposed yet intact roots (Table 3), which may indirectly suggest a better oral health status in this group. However, a recent study conducted on elderly living in a residential home at Turkey ${ }^{20}$, with mean age of 75 years, did not find difference among DF-R and gender. In this study, there was no statistically significant difference between root caries prevalence and gender in any of the age groups.

Epidemiological surveys addressing root caries present some vulnerability or limitation of outcomes. The estimate of root caries prevalence may be impaired by the presence of restorations on this surface, which may have been applied due to caries or not $^{21}$. However, if only untreated carious lesions are diagnosed, the value of examination is considerably reduced. According to Clarkson ${ }^{2}$ (1995), investigations may underestimate more than two thirds of the prevalence.

Despite the vulnerability of epidemiological surveys at these age groups, some aspects as the mean number of sound roots and mean number of present teeth were highlighted; their investigation in studies addressing the tooth root is required.

\section{CONCLUSION}

In this study, root caries prevalence was lower in areas with fluoridated water. Due to the reduced prevalence of edentulism and increased number of people keeping their natural teeth for a longer period, a future increase in root caries is expected, highlighting the importance of studies related to water fluoridation and its relationship with the oral health of adults and elderly, especially referring to tooth root.

\section{ACKNOWLEDGEMENTS}

The authors would like to thank the State Health Secretariat, in the person of the State Coordinator of Oral Health, Maria Candelária Soares, for making the data available. The authors also thank the Oral Health Coordinators of DIRs involved in this study, Nádja M. Abdala, Márcia Regina Angeli Jordão, Airton Dias Pascoal and Wilson Gonçalves, who authorized the use of data from the cities involved. The authors area grateful to the volunteers who accepted taking part in the survey. 


\section{REFERENCES}

1- Burt BA, Ismail AI, Eklund SA. Root caries in an optimally fluoridated and a high-fluoride community. J Dent Res. 1986;65(9):1154-8.

2- Clarkson JE. Epidemiolgy of root caries. Am J Dent. 1995; 8:32934 .

3- Frazão P, Antunes JLF, Narvai PC. Early tooth loss in adults aged 35 - 44: state of Sao Paulo, Brazil, 1998. Rev Bras Epidemiol. 2003;6(1):49-57.

4- Fure S, Zickert I. Incidence of tooth loss and dental caries in 60, 70- and 80-year-old Swedish individuals. Community Dent Oral Epidemiol. 1997;25:137-42.

5- Fure S. Five-year incidence of caries, salivary and microbial conditions in 60-, 70- and 80-year-old Swedish individuals. Caries Res. 1998;32:166-74

6- Guivante-Nabet C, Tavernier M, Trevoux C, Berdal A. Active and inactive caries lesions in a selected elderly institutionalized French population. Int Dent J. 1998;48:111-22.

7- Hopcraft M, Morgan M. Dental caries experience in a young adult military population. Aust Dent J. 2003;48(2):125-9.

8- Hunt RJ, Eldredge JB, Beck JD. Effect of residence in a fluoridated community on the incidence of coronal and root caries in an adult population. J Public Health Dent. 1989;49(3):138-41.

9- Imazato S, Ikebe K, Nokubi T, Ebisu S, Walls AW. Prevalence of root caries in a selected population of older adults in Japan. J Oral Reabil. 2006;33(2):137-43

10- Kalsbeek H, Truin GJ, Van Rossum GM, Van Rijkom HM, Poorterman JH, Verrips GH. Trends in caries prevalence in Dutch adults between 1983 and 1995. Caries Res. 1998;32(3):160-5.

11 - Marthaler TM, O'Mullane DM, Vrbic V. The prevalence of dental caries in Europe, 1990-1995. Caries Res. 1996;30:237-55.

12- Meneghim MC, Pereira AC, Silva FRB. Prevalence of root caries and periodontal conditions in an elderly institutionalized population from Piracicaba- SP. Pesqui Odontol Bras. 2002;16(1):50-6

13- Murray JJ, Pitts NB. Trends in oral health. In: Pine CM Community oral health. Oxford : Wright; 1997. p.126-45.

14- O'Mullane D, Whelton H. Caries prevalence in the Republic of Ireland. Int Dent J. 1994;44(4 Suppl 1):387-91.

15- O'Mullane DM, Whelton HP, Costelloe P, Clarke D, Mcdermott S. Water fluoridation in Ireland. Community Dent Health. 1996;13(Suppl. 2):38-41.

16- Secretaria de Estado da Saúde de São Paulo. Levantamento das condições de saúde bucal - Estado de São Paulo, 1998: Caderno de instruções. São Paulo: Secretaria de Estado da Saúde de São Paulo; 1998.

17-Simunkovi $\ddot{A} \ddagger$ SK, Boras VV, PanduriÄ $\ddagger$ J, ZiliÄ $\ddagger$ IA. Oral health among institutionalized elderly in Zagreb, Croatia. Gerodontology. $2005 ; 22(4): 238-41$

18 - Skudutyte R, Alesejuniene J, Eriksen HM. Dental caries in adults Lithuanians. Acta Odontol Scand. 2000;58:143-7

19- Slade GD, Spencer AJ. Distribution of coronal and root caries experience among persons aged $60+$ in South Australia. Aust Dent J $1997 ; 42(3): 78-184$
20- Ünlüer, S, Gökalp, S, Doðan, BG. Oral health status of the elderly in a residential home in Turkey. Gerodontology. 2007;24:22-9.

21 - Walls AWG, Silver PT, Steele JG. Impact of treatment provision on the epidemiological recording of root caries. Eur J Oral Sci. 2000;108:3-8.

22 - World Health Organization. Oral health surveys: basic methods. $4^{\text {th }}$ ed. Geneva: World Health Organization; 1997. 